\title{
La libertad como un fenómeno financiero entre los esclavos de Río de Janeiro a mediados del siglo XIX
}

\author{
Carlos Eduardo Valencia Villa \\ Universidade Federal Fluminense, Brasil \\ cvalenciavilla@gmail.com
}

\begin{abstract}
Resumen
Este artículo indaga las variables financieras y las relaciones entre ellas que contribuyen a explicar la manumisión que era comprada por los cautivos en Río de Janeiro a mediados del siglo XIX. En particular, analiza el precio de manumisión, el acceso a la moneda por parte de los esclavos y la rentabilidad de la libertad para comprender cómo su relación influyó en la cantidad de individuos que se liberaron. La conclusión es que el precio de manumisión tenía un papel menos destacado que las otras dos variables. La rentabilidad de la libertad influía en las tendencias de la manumisión mientras que el acceso a la moneda intervenía en la generación de los ciclos dentro de esas tendencias.
\end{abstract}

Palabras clave: esclavitud, manumisión, Río de Janeiro, historia económica.

\begin{abstract}
The aim of this paper is to explore the financial variables and the relations among them in order to explain the manumission that was bought by the slaves in Rio de Janeiro in the middle of century XIX. In particular, we want to analyze manumission prices, access to cash by the slaves, and freedom profitability for understanding how the relationship among these variables influenced in the amount of individuals that became free. The outcome is the manumission price had been less important than the other variables considered. Profitability of freedom influenced in manumission tendencies, while the access of cash generated different cycles inside these tendencies.
\end{abstract}

Key words: slavery, manumission, Rio de Janeiro, economic history. 


\section{FRONTERAS}

Durante el esclavismo latinoamericano, algunos individuos consiguieron salir del cautiverio mediante mecanismos legales y legítimos ${ }^{1}$. Esos individuos siempre fueron una minoría de la población. La inmensa mayoría de ellos terminaba sus días como cautivos y pocos eran los que lograban transformarse en horros. Pero, a pesar de que aquel porcentaje fuera pequeño, la cuestión de la manumisión es central para comprender tanto el esclavismo como la configuración de las sociedades coloniales. La manumisión era esencial, tal vez por su papel de mediador entre las tensiones del esclavismo, o por los alivios culturales que traía a los amos, o por la posibilidad que representaba para los esclavos, o por las alianzas potenciales que podía generar. En consecuencia, su trascendencia no puede ser entendida únicamente a la luz de cuántos esclavos pasaron por ella. El fenómeno de la manumisión fue tan importante que, con seguridad, es uno de los caminos expeditos para comprender el pasado colonial. A través de ella, por ejemplo, se puede observar las relaciones entre los grupos sociales, percibir los problemas y tensiones entre los cautivos, o establecer las estructuras jerárquicas dentro de la sociedad. Aquí queremos utilizarla para acercarnos a la economía autónoma de los esclavos.

La economía autónoma de los esclavos hace referencia a las actividades y cálculos económicos que realizaron los cautivos por fuera del control de sus amos. Como es de sobra conocido, muchos esclavos trabajaban por cuenta propia vendiendo mercancías en las calles de las ciudades coloniales, cultivando sus pequeñas parcelas en lo que la historiografía denominó la brecha campesina, prestando servicios como bogas en los ríos, estibadores en los puertos, prostitutas, artesanos, barberos, o mineros y empleados domésti$\cos ^{2}$. En casi todos los sectores laborales que aquella sociedad conoció, los esclavos trabajaban de forma autónoma. Una porción de los ingresos generados en esas actividades era entregada a los amos a título de jornal. Éste era un valor generalmente fijo y que se debía pagar en períodos constantes tales como días o semanas. La otra porción de los ingresos quedaba para los esclavos y con ella debían sostenerse, pagando por su propia cuenta los gastos de vivienda, comida, ropa y demás. Es evidente que en cada contexto y en cada caso individual la composición de esos gastos variaba, pues algunos, como los esclavos de plantaciones, podían no tener que gastar en habitación;

1 El autor agradece al Instituto Colombiano de Antropología e Historia, a la Universidad Nacional de Colombia y a la Universidad Colegio Mayor del Rosario (Colombia) por el apoyo financiero que permitió la investigación en la que se inscribe este artículo. También a los dos comentaristas anónimos que hicieron sugerencias al texto.

2 Son muchos los autores que trabajan estos tópicos. Algunas referencias son Carlos Lima, Rafael Díaz y Ciro Cardoso. 
en cuanto a otros, como los esclavos urbanos, ese costo podía ser el más grande de su conjunto de gastos.

A pesar de que gran parte de los recursos que los esclavos mantenían para sí sólo alcanzaban para financiar los gastos de sostenimiento, también es cierto que en algunas ocasiones esos recursos eran acumulados para posteriormente ser empleados en el pago de las manumisiones. Esto significa que existió una estrategia económica para pagar por la libertad. Claro que la manumisión no es únicamente un producto de esa acumulación. La estrategia económica no era la única estrategia que tenían los esclavos para transformarse en libres. No lo es por dos razones básicas. Primero, porque para acceder a la manumisión existían otros dos caminos alternativos al de la compra: la manumisión gratuita, entendida como aquélla en que los amos concedían la libertad por servicios ya prestados por los esclavos; y la manumisión por pactos de servicios adicionales, es decir, por servicios que serían prestados en el futuro. Segundo, porque los esclavos accedían a la manumisión gracias a condiciones no económicas; condiciones como, por ejemplo, el género del esclavo, su adscripción étnica, su edad, ser parte de alguna familia esclava, y muchas otras. De esta manera, las variables que explican la manumisión van más allá de las variables estrictamente económicas para inscribirse en una dimensión más amplia.

Dicho esto, es importante resaltar que la manumisión no era únicamente un fenómeno económico, sino también una cuestión económica. Muchos esclavos usaron parte de los recursos que adquirían para financiar el pago de su libertad. Es sobre esa estrategia que este artículo trabaja. Sin embargo, repitamos, la manumisión no se reduce a las estrategias que comentaremos aquí. Ella es producto de condiciones sociales e individuales específicas que implican unas elecciones concretas para cada esclavo. Pero aquí sólo discutiremos las variables estrictamente económicas de las manumisiones pagadas con dinero. En particular, queremos revisar tres variables económicas como factores de explicación parcial de la manumisión: el precio de la manumisión, el acceso a la moneda, y la rentabilidad de la libertad.

Aquellos esclavos que compraron su libertad debieron ser sensibles a la relación entre esas tres variables: precio, moneda y rentabilidad. Al final, la manumisión para ellos era una inversión que implicaba usar unos recursos para alcanzar una meta. Así, el cálculo económico debió estar presente. De paso aclaremos que decir cálculo económico no quiere decir capitalismo. Recordemos que el capitalismo es algo mucho más complejo y específico que el cálculo 


\section{FRONTERAS}

económico. Con seguridad, el cálculo económico es algo que está presente en los individuos desde tiempos inmemoriales. El capitalismo, como sistema, ni siquiera se define por la existencia de ese cálculo, ni por la existencia de algún tipo de cálculo específico. Por tanto, afirmar que los esclavos hacían cálculos económicos no implica alguna forma de anacronismo. Este artículo se acerca al problema de la moneda, precio y rentabilidad de la manumisión para el caso específico de los esclavos urbanos de Río de Janeiro a mediados del siglo XIX. Las relaciones entre esas tres variables y las posibles influencias en las tasas y tendencias de la manumisión serán discutidas únicamente para este contexto y no pretendemos que sean generalizables al esclavismo colonial americano.

El gráfico 1 muestra el total de manumisiones entre 1840 y 1871 con un vacío entre 1865 y 1869 cuando Brasil enfrentó la guerra con Paraguay, quinquenio para el cuál no tenemos información. La serie fue construida con todas las cartas de libertad registradas en las notarias primera, segunda y tercera de Río de Janeiro y que hoy se encuentran custodiadas por el Archivo Nacional de Brasil en Río de Janeiro. En total, son 17.650 esclavos, compuestos por 10.259 mujeres y 7.382 hombres, con un pequeño número de casos en los que no fue posible determinar el género. Está conformada por 8.199 esclavos africanos y 9.002 criollos. Otra vez, hay un pequeño porcentaje de individuos a los que no fue posible determinarles su procedencia. Por último, tiene 2.313 adultos, 1.686 ancianos (definidos como mayores de 40 años) y 2.232 niños (definidos como menores de 14 años) $)^{3}$.

3 A pesar del gran tamaño de la serie, el tratamiento que le daremos a los datos será el de muestra estadística. Todos los datos de manumisión provienen de esta misma muestra que en adelante se nombrará como MRJ. El autor quiere agradecer a los miembros de la Línea de Historia Económica de la Universidad Federal de Río de Janeiro por la información y debates con los que se construyó este artículo. 


\section{Gráfico 1: Total de manumitidos en Río de Janeiro, 1840-1871}

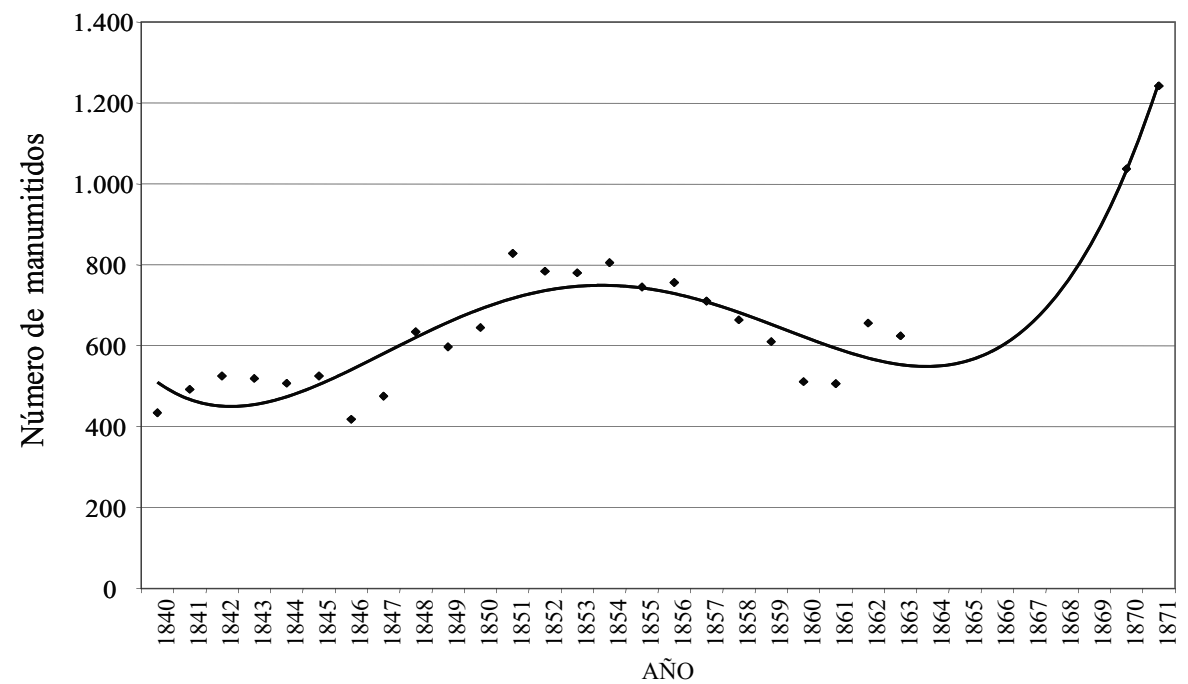

Fuente: $M R J$ y cálculos del autor.

Sin embargo, aquí no trabajaremos con toda la muestra, pues en ella hay 9.079 casos de manumisiones por servicios ya prestados y 3.163 por pactos de servicios adicionales, además de 730 cartas de libertad que no pudimos clasificar como uno de los tres medios generales para salir del cautiverio del que hablamos antes. Así, sólo trabajaremos con los 4.678 casos en los que los esclavos hicieron pagos económicos para alcanzar la libertad. De ese total, 2.941 fueron mujeres y 1.784 fueron hombres; y 2.330 africanos y 2.292 criollos.

El artículo no está dividido por cada una de las variables que analizaremos sino que busca ir estableciendo la relación entre ellas. Así, empezaremos con el contexto monetario, luego el acceso a la moneda para los manumitidos, después la importancia del precio como variable de explicación de la cantidad de manumisiones, de allí retornaremos para valorar la importancia de la moneda como variable de explicación de la manumisión y, por último, enfrentaremos el problema de la rentabilidad de invertir los recursos en comprar la libertad.

\section{El panorama monetario}

Para comprender el tamaño y la importancia del flujo de dinero entre los esclavos, necesitamos tener claro cuál era el panorama de la circulación monetaria 


\section{FRONTERAS}

en la ciudad. Por supuesto, no precisamos de una exposición detallada (Peláez y Suzigan). Simplemente necesitamos algunos elementos de la política económica para así poder valorar el efecto de ellas sobre las oportunidades económicas que tuvieron los esclavos. Para aquellos años, el Banco de Brasil (re-fundado por el gobierno a comienzos de la década de 1850) no tenía la obligación legal de mantener algún nivel de encaje; y situación similar regía para los bancos privados que tampoco tenían el deber de consignar, en el Bando de Brasil, alguna parte de sus depósitos. Es más, durante algunos períodos del siglo XIX los bancos privados podían emitir. Por ejemplo, entre 1851 y 1859 había tres tipos de emisores: el Tesoro Nacional, el Banco de Brasil y los bancos comerciales (IBGE 516). Debido a ese tipo de limitaciones, trabajaremos con los montos de papel moneda en poder del público, definido como toda la emisión menos la caja de los bancos; estamos hablando entonces de todo el papel moneda que estaba por fuera del sistema bancario y cuya circulación, en términos generales, quedaba definida en cuatro períodos (IBGE 519).

Primero, de 1840 a 1853, estable. Segundo, una fuerte expansión hasta 1859 que fue provocada exclusivamente por los bancos privados (Buescu 189). Sin embargo, en 1857 la crisis aparece y el sistema monetario tiene una primera contracción que luego - y éste es el tercer período- se va a profundizar en 1859 debido a los efectos de la crisis mundial sobre la economía brasilera. Entre los meses finales de 1859 y mediados de 1860 , la cantidad de dinero en manos del público se reduce en casi 10 millones de contos, y para finales de marzo de 1861, en 31 millones. Eso significa que en 15 meses la moneda sufre una caída del $40 \%$. Ese nivel de contracción se mantiene durante la primera mitad de la década de 1860 hasta el punto que en 1864 se genera una nueva crisis económica producida por la falta de liquidez del mercado (Buescu 191).

El comienzo de la guerra con Paraguay inició el cuarto período que fue un renovado ciclo de expansión monetaria por consecuencia de la estrategia para financiar el conflicto. Aunque en 1866 los derechos de emisión pasaron a ser exclusividad del Tesoro Nacional como mecanismo para controlar la expansión, el resultado continuó siendo el mismo: crecimiento vertiginoso de la moneda que entre 1865 y 1870 se multiplicaría por 2,2. Con el fin de la guerra, la política de contracción monetaria retornó y durante 1870 la circulación se redujo en 20 millones de contos que representaban el $10 \%$ de toda la moneda que había a comienzos del año. Los esfuerzos por controlar la emisión estaban ligados a la convicción de las autoridades económicas que por ese medio conseguirían mantener una tasa de cambio competitiva para las exportaciones 
(Guimarães 2). Sin embargo, esa idea también tenía un efecto deliberado en el control de la inflación. El gráfico 2 muestra que el comportamiento de los precios estaba ligado a la cantidad de dinero que poseía el público. Los cálculos de Mircea Buescu y de María E. Lobo llegaron a conclusiones similares y demuestran que hay una fuerte correlación entre las dos variables, sin afirmar necesariamente algún sentido de relación causal. Aquí tampoco necesitamos entrar en el debate de causalidad, lo importante es mostrar que la crisis que se inició en 1857 es posible percibirla en la moneda y en los precios. Ambas variables tenían una contracción hasta 1861.

\section{Gráfico 2: Crecimiento anual del papel moneda en poder del público en Brasil y el índice de costo de vida en Río de Janeiro}

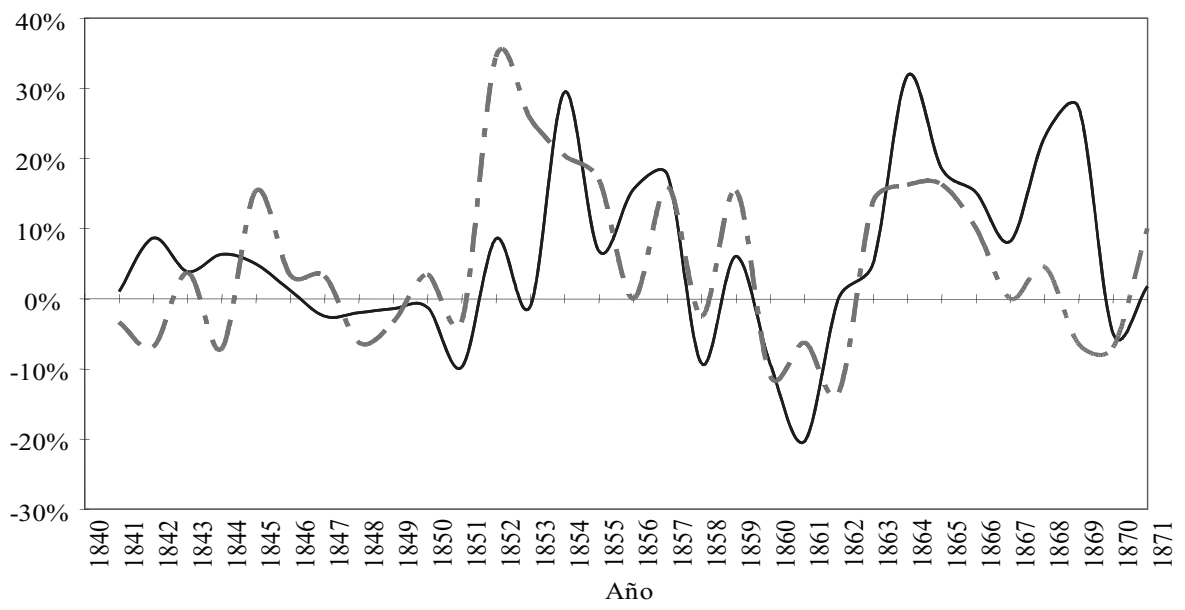

Papel moneda

Costo de vida

Fuentes: María Eulalia Lobo, IBGE y cálculos del autor.

\section{La moneda entre los manumitidos}

Esa relación entre circulación monetaria y precios a mediados del siglo XIX demuestra la existencia de un mercado monetario. Esto es, una importante y mayoritaria porción de la oferta y demanda de mercancías usaba dinero en sus transacciones. En Río de Janeiro, la norma es el intercambio a través de monedas, y eso incluye a los más pobres y a las pequeñas operaciones comerciales (Lobo, 80), tal y como lo demuestra el pago monetario de la manumisión. 


\section{FRONTERAS}

El porcentaje de esclavos que se manumiten por medio de compra y con pago monetario es más o menos constante (Gráfico 3) y oscila en torno al $25 \%$ del total de manumisiones (Gráfico 1). Eso sugiere que por lo menos una cuarta parte de todos los esclavos manumitidos tenía acceso a la moneda, aunque ese porcentaje pudo ser mucho mayor, pues hacer pagos para transformarse en horro era sólo uno de los medios para usar las monedas. Es más, los pagos no siempre eran monetarios sino había bastantes casos de pagos con mercancías, con otro esclavo o con créditos. Por lo tanto, el indicador de pago monetario por la libertad no quiere decir que en esa compra los esclavos usaron todas sus monedas.

\section{Gráfico 3: Cantidad de manumitidos con pagos monetarios y el porcentaje de ellos en el total de manumitidos en Río de Janeiro entre 1840 y 1871}

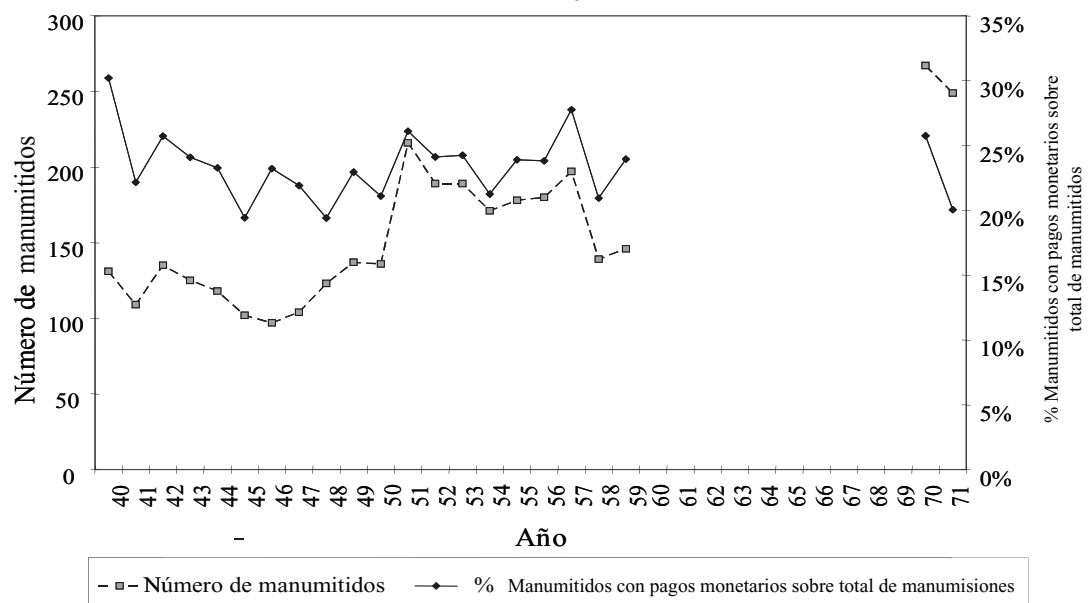

Fuente: $M R J$ y cálculos del autor.

Otra evidencia que expone la información del gráfico es que la cantidad de esclavos que hacían pagos monetarios por la manumisión tiene un ritmo temporal: entre 1840 y 1850 esa cantidad es constante con un promedio anual de 120 individuos; en 1851 salta a 216 y en los años que van hasta 1857 el promedio anual es de 180 ; esto es $50 \%$ más que en la década de 1840 . Para el año de 1857, son 197 esclavos que se transforman en horros mediante pagos monetarios; en el siguiente año esa cantidad se reduce a 139 y en 1859 es de 146. Luego, en 1860 ningún otro esclavo utiliza monedas para salir del cautiverio y esa estrategia sólo reaparecerá en 1870 y 1871 con 267 y 249 individuos, respectivamente. 
En resumen, son 3.438 esclavos que pagaron en moneda por la libertad. El monto total de esos pagos es de 3.209.753 contos de réis a precios de 1870 . Por supuesto, estamos hablando del total para 32 años, pero a pesar de eso es un valor admirable y del que ni la historia económica ni la historiografía de la esclavitud tienen conciencia. Para demostrar esa importancia veamos el gráfico 4. En ella comparamos el total de pagos monetarios anuales por la manumisión con el total de inversiones hechas en las grandes haciendas del Valle del Paraíba, definidas como aquellas mayores a 200 alqueires de tierra o con más de 100.000 pies de café y 60 esclavos (Fragoso 88). El resultado es aun más revelador: de las cinco comparaciones que se pueden hacer, en tres el total de pago anual de los esclavos es mayor que las inversiones de ese mismo año en esas haciendas. En las otras dos, la manumisión alcanza el 78\% y 96\%.

\section{Gráfico 4: Pagos monetarios por la manumisión en Río de Janeiro comparados con las inversiones en grandes haciendas cafeteras del Valle del Paraíba.}

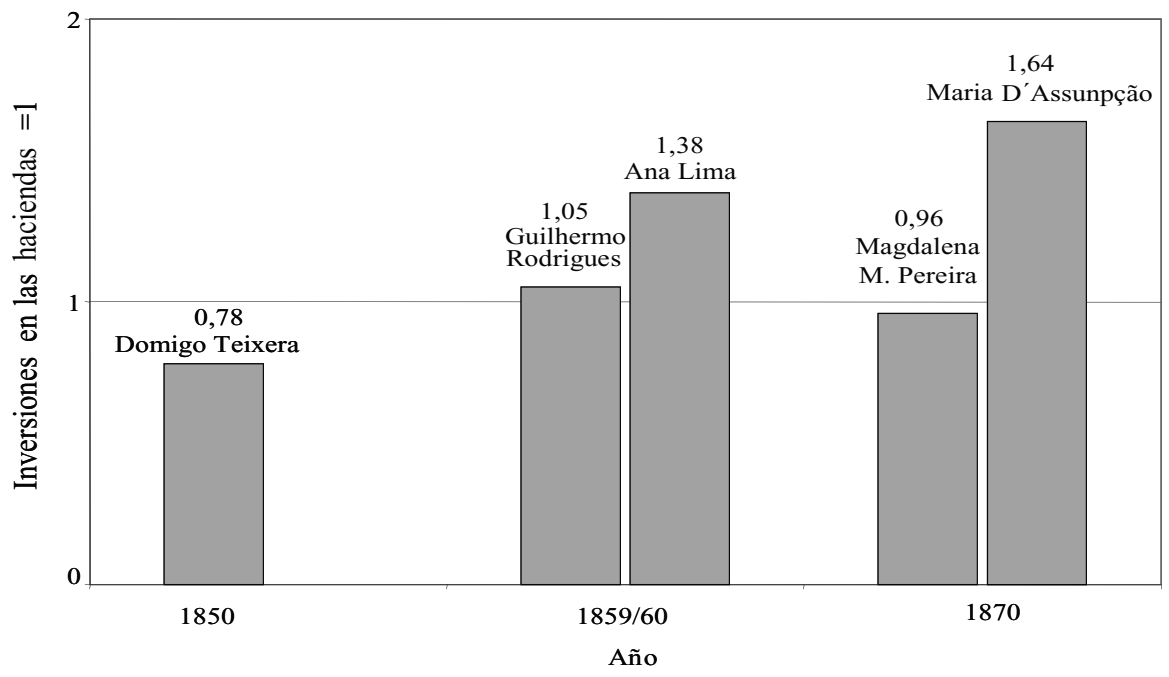

Fuentes: Fragoso, MRJ y cálculos del autor.

Eso significa que, por ejemplo, en 1850 la gran hacienda de Domingo Teixeira Alves tiene inversiones por 75.989 contos, y los esclavos en el mismo año hacen pagos nominales para la manumisión por 59.301 contos, lo que representa el $78 \%$ de la hacienda. Para 1860 no hay pagos monetarios, pero si comparamos los hechos en 1859, que nominalmente son 155.610 contos, con los 147.924 contos de Guilhermo Francisco Rodrigues o con los 112.360 contos 


\section{FRONTERAS}

de Ana Lima Machado, ambos en 1860, lo que encontramos es que el total pagado por los esclavos fue mayor en $5 \%$ y en $38 \%$ que las inversiones de los respectivos hacendados.

Pero antes de que se me mal interprete, aclaremos varias cosas. Lo que estoy afirmando es que en el monto agregado, la economía de los manumitidos está lejos de ser aquella cosa minúscula y despreciable que algunos creían. En el total, los esclavos mueven recursos monetarios que superan los recursos de un rico hacendado del Valle del Paraíba. Empero, para poder hacer eso, los horros tienen que ser más de 130 en 1850, más de 140 en 1859 y más de 260 en 1870 , comparados con un solo hacendado. La riqueza está concentrada y los esclavos son pobres. Nadie duda de eso. Pero los esclavos participan en el mercado monetario y los recursos generados por ellos de forma autónoma son importantes.

\section{La elasticidad-precio de la demanda por la manumisión}

Establecida la vitalidad de la circulación monetaria entre los esclavos, pasemos a ver la importancia del precio de la manumisión para determinar la cantidad de esclavos que deciden pagar por la libertad. En otras palabras, intentemos saber si los esclavos son elásticos al precio de su libertad, pues el sentido común podría sugerir que si los precios bajan es posible que más individuos paguen para pasar a ser horros; en sentido contrario, si los precios suben, sería esperable que los individuos enfrenten un desestímulo económico y que menos paguen por su libertad.

La primera cuestión para saber si existe esa elasticidad precio es conocer los precios reales de la manumisión; esto es, debemos transformar los valores nominales en reales para poder establecer si el monto de la manumisión se aumentó o se redujo. El indicador evidente para esa transformación es un índice de comportamiento de precios. Aquí usamos el propuesto por Mello ("The Economics"). El gráfico 5 muestra la serie de precios en reales, a valores de 1870 para la manumisión. Como se puede ver, existió estabilidad en la primera década, en la segunda había un fuerte incremento y en la tercera, una contracción. Ese movimiento en los precios no está claramente correlacionado inversamente con la cantidad de manumisiones que mostramos en el gráfico 1, pues por pequeños períodos las dos series se comportan de forma paralela y por períodos, de forma opuesta, lo cual no permite afirmar que sea el precio la variable que define la cantidad de manumisiones efectuadas.

Ahora bien, esa comparación la estamos haciendo con la serie de todos los manumitidos, es decir, incluyendo las libertades por servicios ya prestados 


\section{Gráfico 5: Precio promedio real de las manumisiones en Río de Janeiro, 1840-1871}

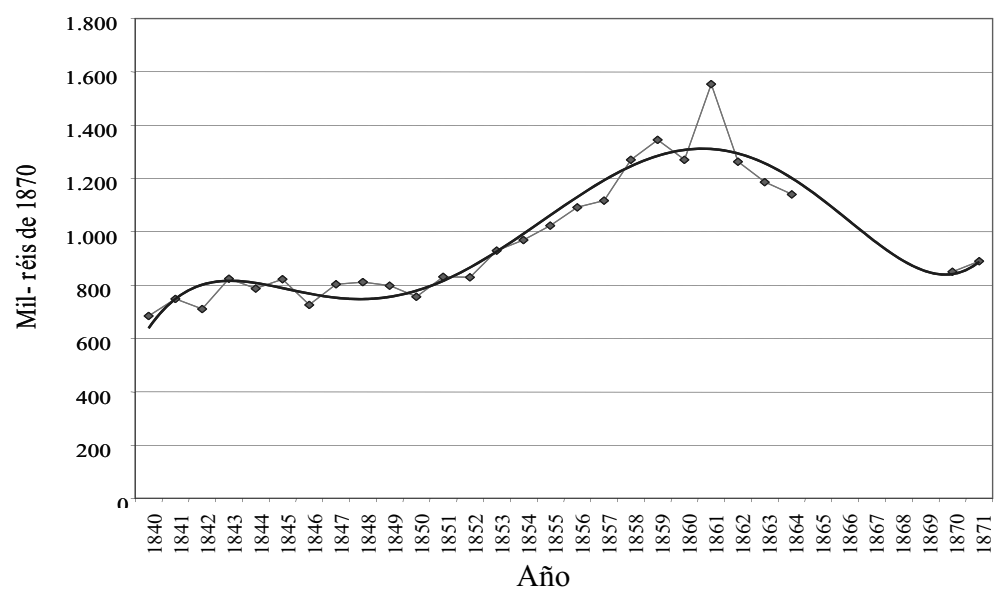

Fuentes: MRJ, Mello (“The Economics”) y cálculos del autor.

y por pacto de servicio adicional lo cual podría generar una distorsión, pues ese tipo de operaciones no necesariamente se verían influenciadas por el precio. Así, observemos las series de precio y volumen de manumisión sólo para aquellos casos en los que se efectuó algún tipo de pago. El gráfico 6 expone esa relación y deja ver que tampoco existe la correlación inversa que el sentido común podría sugerir. Por ejemplo, entre 1842 y 1846 los precios estaban estables y las manumisiones caían; luego, hasta 1851 los precios no se movían de forma significativa pero las libertades crecían. Después, parece que la situación fuera la esperada: al incremento en los precios le seguía una caída en los volúmenes, pero esto sólo duró hasta 1855 cuando ambas series volvían a moverse de forma paralela. Y seguía así durante el resto del período: momentos de correlación inversa y momentos de correlación directa. Momentos que son muy cortos como para proponer que exista una relación menos caótica que ésa. 


\section{Gráfico 6: Comparación entre el precio real de las manumisiones con pagosy el total de manumisiones con pagos}

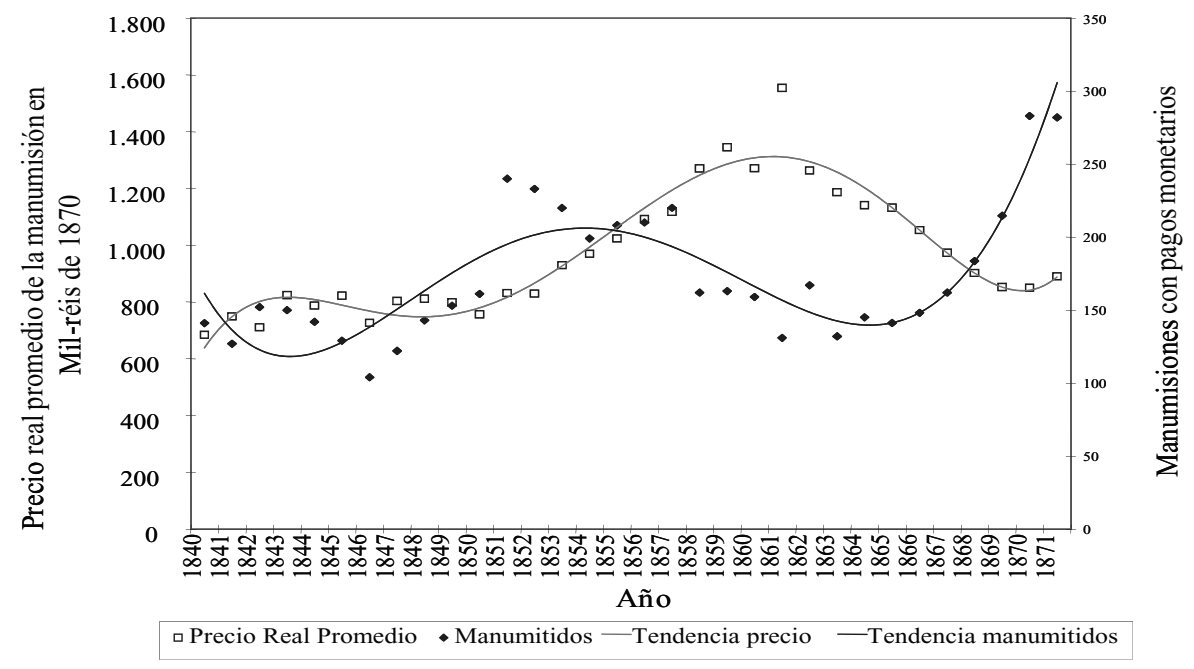

Fuentes: $M R J$, y cálculos del autor.

\section{Los impactos de la moneda en la vida de los manumitidos}

Si el precio de la manumisión no es la variable que explica - aunque pueda ser parte de un conjunto de variables-, intentemos saber si son las oscilaciones en la cantidad de moneda en poder del público las que contribuyen a comprender el comportamiento temporal de la cantidad de manumisiones. Lo esperable es que, como la cantidad de dinero entre los esclavos que compran la manumisión era importante, los ritmos de contracción y expansión de la circulación monetaria estén relacionados con los ciclos de la manumisión.

Desafortunadamente, no tenemos series de circulación solamente para Río de Janeiro y estamos presentando las series para todo Brasil. Aunque esto podría ser un problema, es bueno tener en cuenta que durante el siglo XIX la gran mayoría de las regiones brasileras enfrentaban carestías monetarias, mientras que Río de Janeiro tenía comparativamente una abundancia (Bentivoglio 18 y 21). Por lo tanto, con toda seguridad, la tendencia en la ciudad acompaña de forma paralela la tendencia en el país. 


\section{Gráfico 7: Comparación entre el papel moneda en poder del público en Brasil y la cantidad de manumisiones monetarias en Río de Janeiro entre 1840 y 1871}

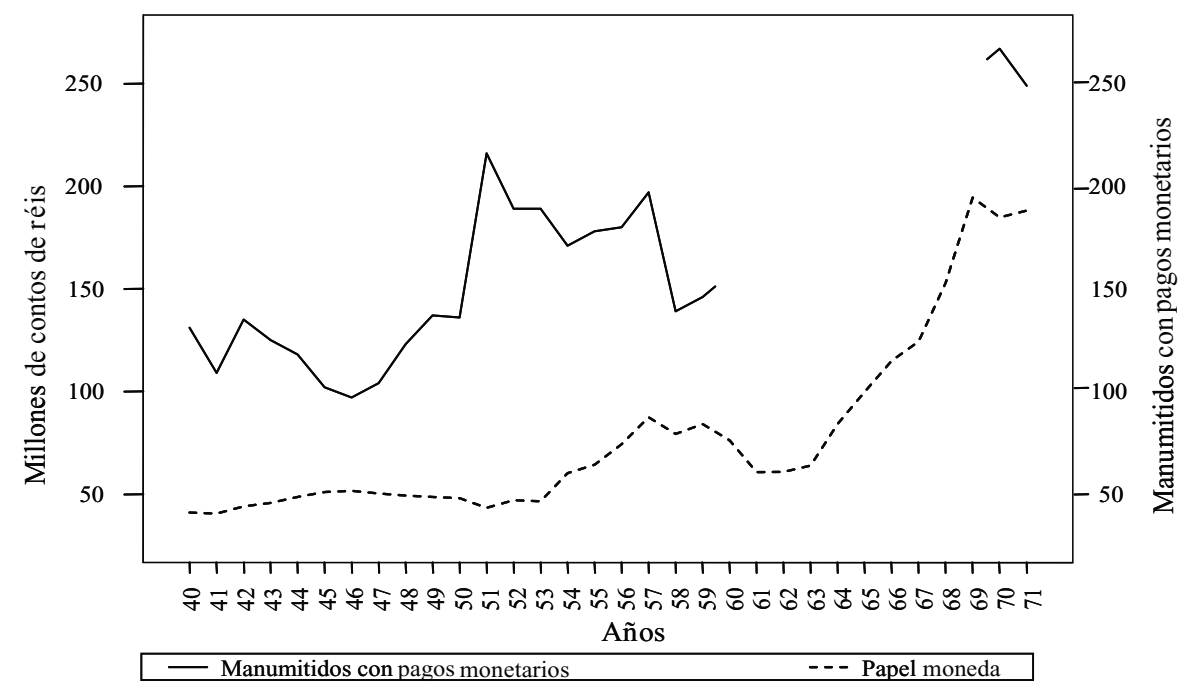

Fuentes: $M R J$, IBGE y cálculos del autor.

Podemos asegurar que no hay una correlación evidente entre las tendencias de manumisiones pagadas monetariamente y la tendencia del total de la circulación monetaria en Río de Janeiro. Y por tanto, podríamos concluir con una afirmación como la siguiente: el ciclo de la manumisión carioca no está influenciado por la circulación de moneda. Con ella, los esclavos estarían alejados del mercado y muchas investigaciones de historia económica podrían estar tranquilas. Con todo, antes de desistir, demos una última mirada a la relación entre el papel moneda en poder del público y manumisión e intentemos colocar un poco de presión sobre esa relación.

Antes mostramos que el movimiento en los precios de las mercancías estaba acompañado por el movimiento en la cantidad de moneda en circulación. Si revisamos el gráfico 8, encontramos que los precios de las manumisiones tienen una relación con la cantidad de papel moneda. Pero esa relación es compleja. Entre 1840 y 1857, parece que son directamente proporcionales; después, entre 1857 y 1864, parecen tener una relación inversamente proporcional: el papel moneda se contrae y los precios nominales crecen. Y al final, entre 1865 y 1871, la moneda crece y los precios tienen una caída que es menos que proporcional a ese aumento monetario. 


\section{Gráfico 8: Comparación entre tendencias del papel moneda en circulación y los precios nominales de las manumisiones en Río de Janeiro, 1840-1871}

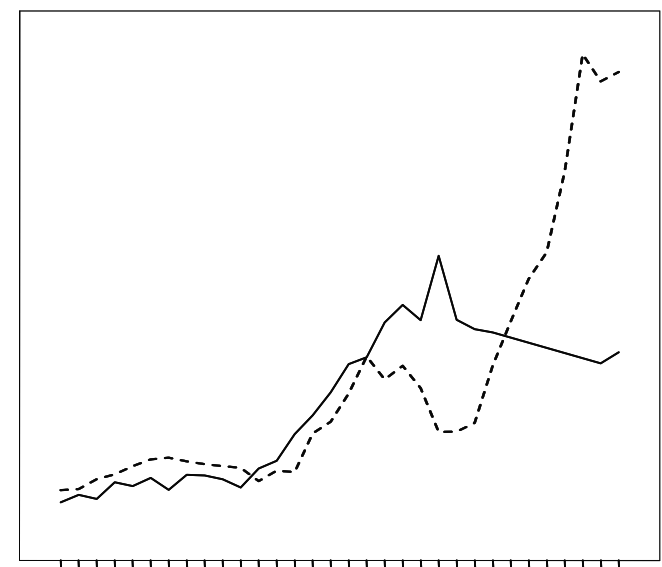

Años 1840-1871

\begin{tabular}{|ll|}
\hline $\begin{array}{l}\text { Promedio del precio nominal } \\
\text { de la manumisión }\end{array}$ & $--\begin{array}{l}\text { Papel moneda en poder } \\
\text { del público }\end{array}$ \\
\hline
\end{tabular}

Fuentes: $M R J$, IBGE y cálculos del autor.

Para comprender esa relación, examinémosla un poco más de cerca. Desde 1852 tenemos información del papel moneda en poder del público por trimestre y podemos aprovecharla para compararla con el promedio de los precios de manumisión en cada trimestre hasta 1859 , año en que los pagos con moneda desaparecieron. Los índices de correlación son bastante confiables y con certeza los precios que pagaron los esclavos por la libertad oscilan por influencia de la circulación monetaria, tal y como lo muestra la gráfica ${ }^{5}$.

Que esas dos variables estén correlacionadas demuestra la participación de los esclavos en la circulación monetaria. Pero ya calculamos la elasticidadprecio de la libertad para los esclavos y lo que hallamos fue que ellos no se transformaban en horros de forma proporcional a los cambios en los precios reales de las manumisiones. Lo extraño es que, al mismo tiempo, los precios que pagaron por la libertad están relacionados con la cantidad de moneda. Eso quiere decir que tenemos un triángulo bien interesante: el precio de la libertad es elástico a la moneda pero la cantidad de manumisiones no es elástica al precio de la libertad.

5 Calculamos los siguientes indicadores con sus respectivos resultados: Pearson 0,82; Kendall 0,7 y Spearman 0,88 . 


\section{Gráfico 9: Comparación entre tendencias del promedio trimestral de los precios nominales de la manumisión y la cantidad de papel moneda en poder del público. Río de Janeiro, 1852-1859}

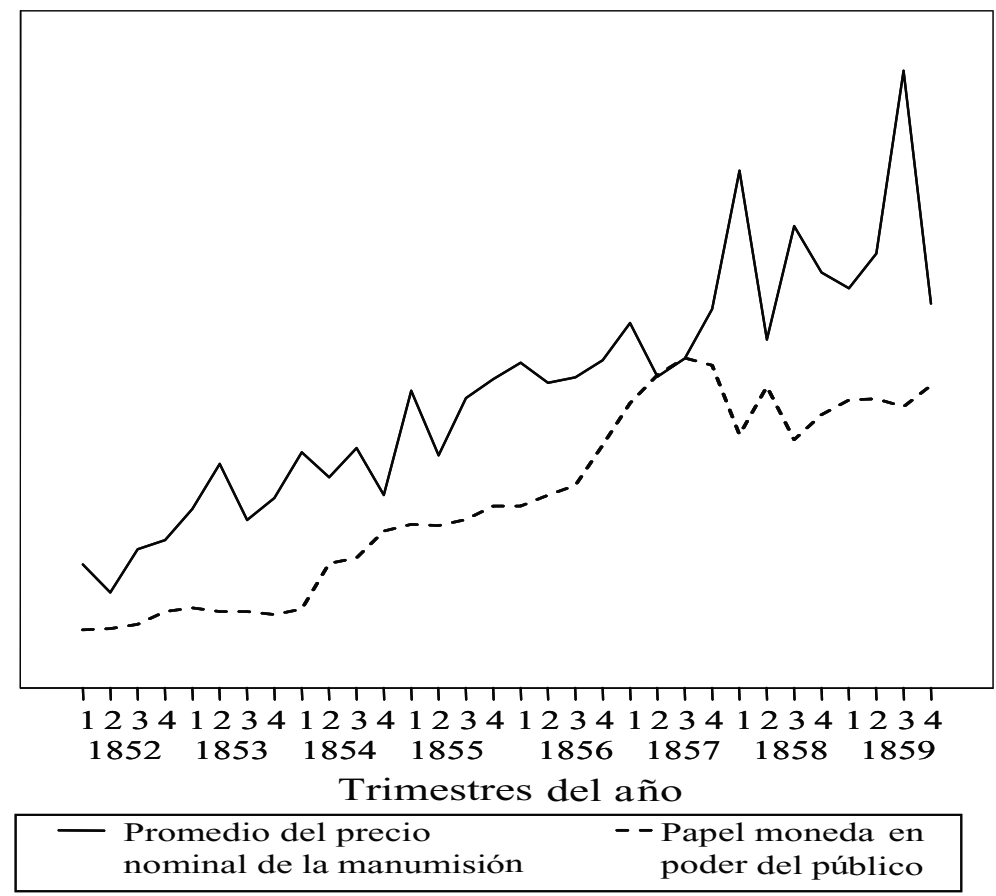

Fuentes: $M R J$, IBGE y cálculos del autor.

Nuestra hipótesis es que esa relación se explica por la participación de los esclavos en el mercado. Ellos ofrecen artículos y servicios que tienen precios que oscilan al ritmo de la cantidad de moneda en la ciudad; por lo tanto, el dinero que ellos consiguen depende de la cantidad que esté en circulación. Cuando es abundante, los precios de las mercancías ofrecidas por los esclavos crecen y así se incrementa la cantidad de moneda a la que acceden los esclavos. Por el mismo mecanismo, cuando la moneda y los precios bajan, ellos ven reducido su inventario monetario. Los esclavos son inelásticos al precio de la libertad, pero los pagos monetarios por la manumisión están correlacionados con la cantidad de moneda disponible. Como acabamos de explicar, nuestra hipótesis es que esa situación es consecuencia de la participación esclava en los mercados urbanos. Ahora intentemos probar si nuestra explicación es válida. 


\section{FRONTERAS}

En la primeras páginas mostramos los ciclos de circulación monetaria: entre 1840 y 1853 , estabilidad; entre 1853 y 1859, crecimiento pero con el comienzo de la contracción en 1857; evidente crisis entre 1859 y 1864; y, finalmente, fuerte incremento hasta 1871 . Ahora comparemos esos ciclos con los que presentamos para las manumisiones compradas con moneda: entre $1840 \mathrm{y}$ 1851, estabilidad; entre 1851 y 1857, crecimiento; entre 1857 y 1859, caída; entre 1860 y 1864 , crisis total de esa estrategia de manumisión; y, por último, entre 1870 y 1871 , una fuerte alza. Esa coincidencia entre ciclos es ya de por sí interesante. Es evidente que el ciclo monetario y el ciclo de manumisiones están vinculados. También es evidente que la moneda no es la única variable que explica; como al comienzo afirmamos, la composición demográfica de las familias, las oportunidades diferentes según género, las estrategias de atribución de identidad, la expansión del mercado y algunas otras variables también contribuyen a la explicación del por qué los esclavos cariocas del siglo XIX se manumiten más en ciertos años que en otros. Sin embargo, la importancia de esas características no quiere decir que las variables financieras no tengan relevancia en la comprensión de la manumisión. Así que continuemos con la exposición de los vínculos entre finanzas y libertad.

\section{Gráfico 10: Comparación trimestral entre cantidad de manumisiones monetarios y papel moneda en poder del público. Río de Janeiro, 1852-1864}

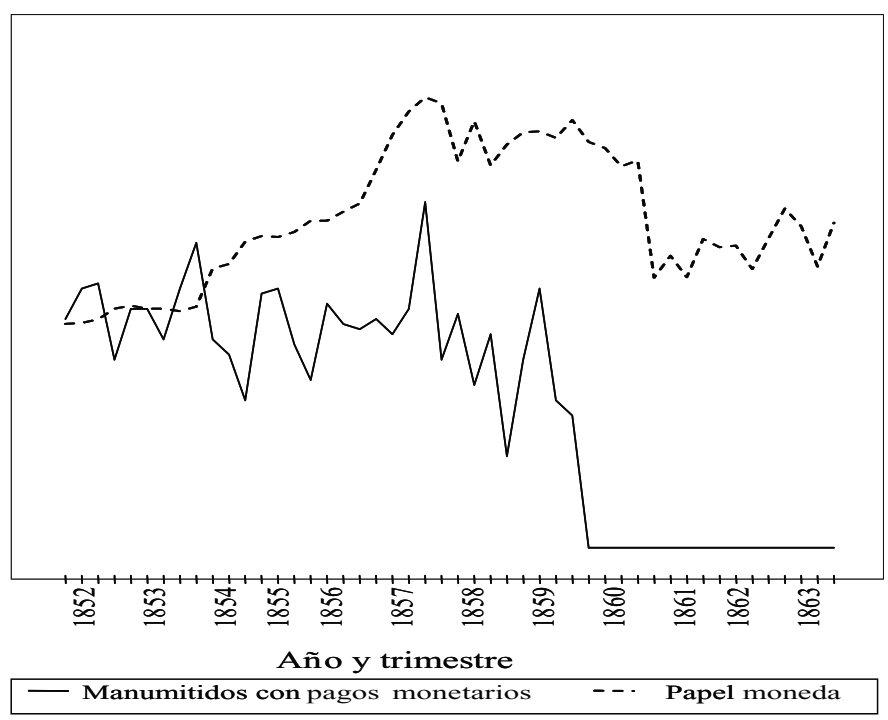

Fuentes: $M R J$, IBGE y cálculos del autor. 
Aprovechemos un poco más la información trimestral y miremos con detalle el período entre 1852 y 1864, que sin lugar a dudas es el más interesante. En especial observemos tres momentos de la secuencia que muestra la gráfica 10. Comencemos con el tercer trimestre de 1857. En ese momento, el papel moneda en poder del público alcanza su máximo y en ese mismo trimestre se da el máximo en el número de manumitidos pagando en moneda por la libertad. Pasemos ahora al segundo trimestre de 1859, cuando la moneda en circulación se recupera de la fuerte caída que vivió y cuando, de inmediato, los esclavos elevan la cantidad de pagos monetarios por la manumisión. Y, finalmente, miremos el período desde el último trimestre de 1859 hasta marzo de 1861, cuando la caída en la circulación de numerario fue del $40 \%$; ésta fue seguida por la contracción y posterior desaparición de los pagos monetarios. Después de ese momento, ya no hay esclavos que usan moneda para ser libres.

De este modo, podemos afirmar que lo que estamos viendo no son sólo esclavos que están en transacciones monetarias, sino esclavos que son muy sensibles a los cambios en la circulación de numerario. En realidad, la pobreza implica vulnerabilidad a las políticas monetarias del Imperio. En otras palabras, estos esclavos están lejos de las economías naturales o de la autarquía. Con toda tranquilidad podemos decir que los esclavos cariocas de estos años están en economías monetarias. Esa sensibilidad a los cambios en la circulación monetaria la expone el gráfico 11. En ella calculamos el incremento o decrecimiento en la cantidad de moneda en comparación con la cantidad que existía en el último año corrido. Por ejemplo, en el último trimestre de 1852, la cantidad de moneda que circulaba era mayor en un $4 \%$ a la que había circulado al comienzo de ese año. Otro ejemplo, en el segundo trimestre de 1854 había un $12 \%$ más de moneda circulando de la que hubo en el año que va de marzo de 1853 a marzo de 1854 . Un último ejemplo, después de un crecimiento de un $12 \%$ en el segundo trimestre de 1854 , el tercer trimestre vuelve a presentar un alza de $9 \%$ en comparación con lo que circuló entre junio de 1853 y junio de 1854 .

Cada trimestre entre 1852 y 1857 tenía un poco más dinero en circulación. Esos incrementos marginales son los que eran percibidos por los esclavos para acceder a las monedas que serían usadas para comprar la manumisión. Después de 1857, las caídas marginales de la disponibilidad de moneda eran vertiginosas: en el segundo trimestre de 1858, la caída era del 10\% en comparación con lo que circulaba entre junio de 1857 y junio de 1858 . Y, a pesar de esa caída, cada nuevo trimestre de 1858 implicaba que circularan menos monedas. Para 1859, este índice de circulación marginal de moneda se elevó en 


\section{FRONTERAS}

menos del 5\%, lo que es más bien poco si consideramos que la circulación se venía restringiendo sistemáticamente. Sin embargo, los esclavos percibían ese pequeño cambio y volvían a comprar la libertad con monedas. Finalmente, la contracción marginal pasó a niveles dramáticos del $25 \%$ sin ninguna recuperación posterior. Y ya sabemos que eso implicó que los esclavos no volvieran a comprar manumisiones con dinero.

\section{Gráfico 11: Variación de la cantidad trimestral de moneda en poder del público en comparación con la circulación en el año corrido. Brasil, 1852-1871}

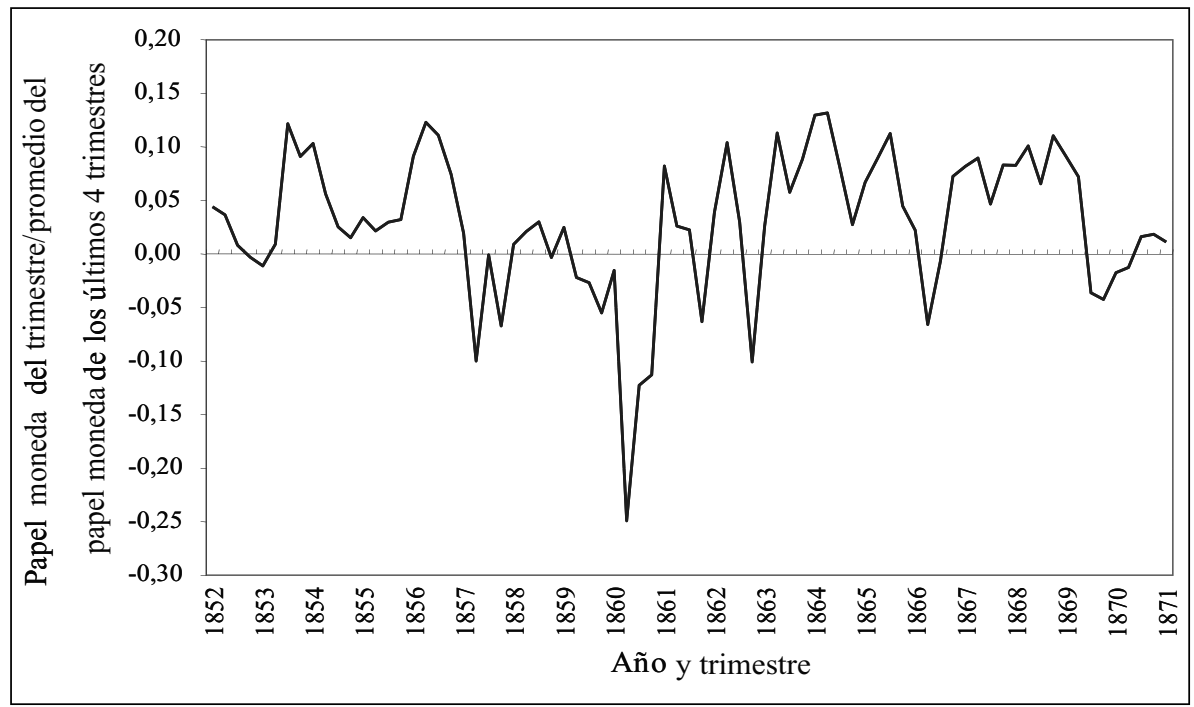

Fuentes: IBGE y cálculos del autor.

Es claro que la crisis económica brasilera (y mundial) de finales de la década de 1850 también alcanzó a los esclavos urbanos de Río de Janeiro, ya que ellos participaban en los intercambios monetarios de la ciudad. Ahora intentemos una indagación sobre el tipo de participación de los esclavos en esos intercambios.

Como la historiografía ya demostró, muchos esclavos conseguían recursos directamente al alquilarse autónomamente. Por lo tanto, sería posible que el acceso a la moneda sea exclusivamente mediante esos negocios. Sin embargo, las evidencias empíricas sugieren una combinación del alquiler autónomo del 
trabajo propio y la participación en la venta de productos. Es decir, los mercados monetarios en los que participaban los esclavos son: trabajo y mercancías (bienes y servicios).

Comparemos la tendencia del valor real de los jornales y el número de esclavos que se manumiten a través de pagos monetarios. Según el gráfico 12, existe un vínculo entre esas dos variables, pero ese vínculo no explica completamente el movimiento en la compra de la libertad. En la primera década, pareciera que las oscilaciones en los jornales están acompañadas por las manumisiones; infortunadamente, los datos de jornal son pocos y no permiten inferencia. Después, entre 1851 y 1857, las series son más claramente paralelas y podríamos decir que para esos años y, en gran medida, el jornal explica ese tipo de manumisión.

\section{Gráfico 12: Manumisiones monetarias y jornal mensual real de esclavos de ganho en Río de Janeiro, 1840-1871}

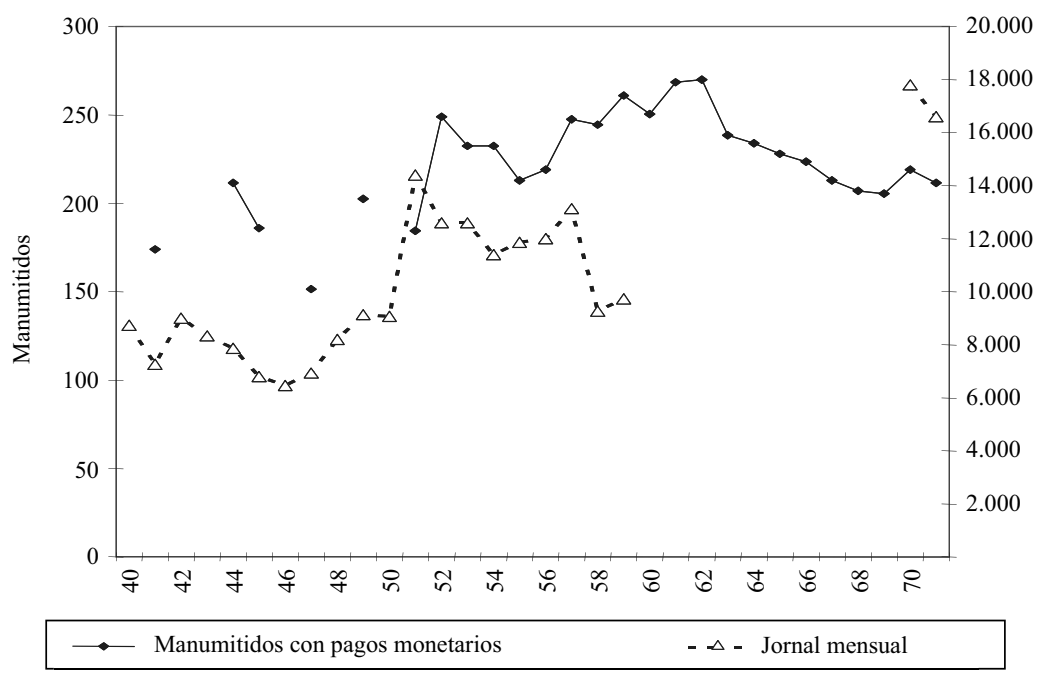

Fuentes: Mello, $M R J$ y cálculos del autor.

Después de 1857, asistimos a la caída de la manumisión monetaria y después de 1860, a su completa desaparición. Ese movimiento no tiene ninguna explicación en los jornales, pues entre 1857 y 1865 los valores reales (no sólo los nominales) continuaron subiendo. Claro, ese valor del jornal es un indicador más que un dato completamente seguro de cuánto recibían los esclavos que se alquilaban autónomamente. Pero, a pesar de eso, es un buen indicador acerca 


\section{FRONTERAS}

de la tendencia de ese tipo de ingresos; esto quiere decir que el jornal no explica completamente el acceso que tuvieron los esclavos a la moneda. Así, la conclusión es que los esclavos cariocas de mediados del siglo XIX accedían a la circulación monetaria y que este acceso dependía de alquilar autónomamente su fuerza de trabajo, pero, también, de la participación en el mercado de artículos y servicios.

\section{La rentabilidad de la inversión en la libertad}

Los esclavos urbanos cariocas de mediados del siglo XIX accedían a la moneda por su participación en el mercado de trabajo y de mercancías. Ahora bien, ellos debían decidir cómo emplear esos recursos y la decisión de cómo usarlos era bastante compleja: los esclavos eran individuos pobres cuyos márgenes de error eran bien pequeños. Si ellos erraban, con certeza el impacto de ese error era formidable en sus condiciones de vida. Con todo, y sin olvidar esa pobreza, las cantidades de dinero que tenían los esclavos para invertir no era pequeña. Antes señalamos algunas comparaciones con los grandes hacendados del rico Valle del Paraíba, ahora vamos a ofrecer otra comparación: según los datos de María Eulalia Lobo (179), en 1856-1857 había en Brasil 1.346 fábricas, de las cuales 1.280 tenían por capital menos de un millón de réis. En esos mismos años, el precio promedio de manumisión fue de 865.150 y 905.952 réis; eso quiere decir que los esclavos que pagaban por la libertad estaban invirtiendo un capital similar al $95 \%$ de las fábricas brasileras de aquellos años. Así, como los dueños de esos negocios esperaban que la inversión en ellos fuera rentable, los esclavos también esperaban que emplear sus recursos en ser libres implicara mejores condiciones de vida (claro, no únicamente en términos económicos, pero sin lugar a dudas también esperaban mejorías en sus condiciones económicas), tanto para ellos como para sus familias.

Ahora bien, la libertad no era la única opción posible para esos recursos. Por ejemplo, algunos esclavos compraron otros esclavos y así pudieron recibir el jornal que sus esclavos producían. Esquematizando este ejemplo, un esclavo podía decidir entre comprar su libertad y ahorrar el jornal trasladado a su amo, o continuar en la esclavitud pero comprando un esclavo que a su vez le entregaría su jornal; en ambas situaciones habría una rentabilidad específica. Algunos esclavos que hicieron esto aparecen en las fuentes, pues varios de ellos pagaron su manumisión entregando al esclavo que antes habían comprado. Entre varios ejemplos, tal fue el caso de Manuel Congo que en 1842 pagó su libertad entregando para su amo a la esclava Constancia Cabinda (ANB, oficio 2, livro 75, f: 435 v., 25/02/1845). Un poco más interesante fue la manumisión 
de João Benguela. Él estaba avaluado en un millón de réis y pagó con Antonio Congo que tenía un precio de 700.000 réis; para ajustar cuentas, João pagó en efectivo la diferencia de 300.000 (ANB, of. 2, 1. 75, f: 638 r., 28/02/1845).

Otros esclavos preferían endeudarse para conseguir el dinero para pagar por la libertad. Otros, en cambio, preferían pagar de contado y en efectivo, como Manuel Cabinda que pagó 700.000 réis explícitamente en billetes de banco (ANB, of. 1, 1. 38, f. 65 r., 16/09/1841). Así, cada esclavo tenía una rentabilidad diferente de acuerdo con su precio de manumisión, con los ingresos que tenía y con las formas de pagar por la libertad. Para conocer esa rentabilidad, usamos la Tasa Interna de Retorno (TIR) que podemos definir como el índice que consigue igualar a cero todos los ingresos y egresos del flujo de caja de una inversión. La TIR es el indicador más común para conocer la rentabilidad de una inversión, entre otras cosas porque permite incorporar el tiempo y los saldos específicos de las rentas que se reciben y los costos en los que se incurre.

Claro que los esclavos no hacían el cálculo de la TIR para decidir si comprar o no la libertad. Tampoco estamos buscando saber si lo hacían. Lo que queremos saber es si estaban haciendo un buen negocio cuando compraban la libertad. De paso aclaremos que la TIR y los otros indicadores económicos - como la elasticidad-precio para la demanda o los rendimientos marginales - no son herramientas metodológicas susceptibles de ser acusadas de anacrónicas, pues todos ellos no tienen, ni pretenden tener, un estatus más allá del de indicador. Ellos solamente muestran si ocurrió, o no, alguna cosa; las explicaciones para comprender lo que muestran los indicadores son las que podrían llegar a ser anacrónicas. Por ejemplo, si la TIR de una inversión tiene un valor, la explicación acerca de por qué ella tiene ese valor es lo que no puede ser anacrónico. No la TIR en sí misma. En ese sentido, los indicadores no son explicaciones, son constataciones que deben ser explicadas.

Más aún, es importante percibir que inversiones con TIR positivas (o mayores al costo de oportunidad) no implican que necesariamente los agentes, solamente por eso, deseen o puedan hacer ese negocio, pues otras variables - como la liquidez y barreras institucionales - son tenidas en cuenta al momento de decidir si se lleva a cabo una inversión. Así podría ocurrir con la libertad. Que ella llegue a tener rentabilidades positivas no quiere decir que todos los esclavos podían acceder a ella. Para conocer la TIR de una inversión es necesario saber el flujo de caja, esto es, los momentos en los que se dan los ingresos y egresos del negocio. Cuando un esclavo compra la libertad hace 


\section{FRONTERAS}

una inversión inicial y gracias a ella va a recibir unos retornos económicos. Ese retorno básicamente es dejar de pagar el jornal a su amo y poder mantener esos recursos para sí. Por tanto, esquematizando, el flujo de caja consiste en una inversión inicial igual al pago por la manumisión y unos retornos periódicos iguales a los valores de jornal que el esclavo pagaba para su amo.

Para calcular la TIR, construimos un flujo de caja particular para cada esclavo al que conocíamos la edad al momento de salir del cautiverio. Así, nuestra muestra de 4.678 casos fue reducida a los 1.390 individuos de los que disponemos su edad: 474 niños, 671 adultos y 245 ancianos. No trabajaremos con aquellos casos de los que tenemos una referencia a la edad pero no un dato más o menos preciso; por ejemplo, aquellos casos en los que se dice que el manumitido es niño, anciano o joven. Esto es porque necesitamos la edad para calcular el indicador del jornal que podría estar percibiendo el esclavo. Para explicar cómo se construyó el flujo de caja para cada esclavo, ofrecemos aquí un ejemplo. El hijo de Joaquina Parda fue manumitido en 1853 por un valor de 450.000 réis, que fueron pagados de contado. Cuando él fue liberado era un recién nacido, así entre 1854 y 1859 asumimos que no contaba con jornal; después de ese año, suponemos que él comenzó a ganar algún dinero que se iría incrementando hasta llegar a los 19 años cuando alcanzaba el máximo. Y así se mantenía hasta los 40 años cuando su jornal empezó a reducirse hasta los 60 años cuando desapareció completamente. Sin embargo, el cálculo para él no fue necesario llevarlo tan lejos, pues la esclavitud terminó en Brasil en 1888 cuando él tenía 35 años y, por lo tanto, su flujo de caja terminó en ese momento, dando una TIR del 11\%. Igual cálculo hicimos con cada uno de los 1.390 manumitidos, muestra que consideramos bastante grande y representativa. Para saber los jornales en el flujo de caja suponemos que entre los 0 y 4 años no se perciben ingresos; entre los 5 y 9 , éstos son del orden del $10 \%$ del jornal anual presentado en la gráfica 12; entre los 10 y 14 años, es del $50 \%$ de ese valor; de los 15 a los 18 es del 75\%; y después de los 19 años es del 100\%; finalmente, después de los 40 años es del $50 \%$. Parecería que estos porcentajes son vitales en el cálculo de la rentabilidad pero, en la realidad, por cada $10 \%$ que se mueva para arriaba o para abajo, el resultado de la TIR se modifica en menos de $1 \%$, lo cual muestra la alta estabilidad de los resultados que luego expondremos.

Supusimos en el cálculo que los esclavos trabajaban entre 250 y 280 días (Lima) que quiere decir un poco más de 8 meses por año, pero optamos por los 8 meses exactos, pues preferimos subestimar la tasa y no sobreestimarla. También calculamos que luego de los 60 años no se percibía ingresos y siempre 
que un manumitido llegara a esa edad, el flujo de caja terminó. Para aquellos esclavos que no alcanzaron esa edad, el flujo terminó en 1888 cuando se decretó la emancipación total. También sabemos que es posible que cuando un esclavo se transformó en manumiso consiguiera elevar sus ingresos más allá del ahorro del jornal con el que estamos trabajando, pues él tenía una nueva condición social y por ella podía recibir ingresos diferenciados. Por tanto, las rentabilidades que mostramos aquí están subestimadas y pueden ser mayores. Bajo estos supuestos, todos los grupos etarios de esclavos menores a 55 años presentan promedios de rentabilidades positivas. Como era de esperar, los individuos que conseguían ser libres entre los 15 y los 29 años eran los que obtenían mayores tasas de retorno. Tal vez para algunos lectores resulte evidente que la libertad tenga una rentabilidad mayor a cero. Sin embargo, no siempre y no en todos los lugares fue así. Por ejemplo, cálculos similares para los esclavos urbanos de Bogotá en el siglo XVII sugieren que, para la gran mayoría de los esclavos, la libertad no era una inversión rentable (Valencia).

Otra información es que al comparar la rentabilidad de la libertad para los esclavos, ella resulta más alta que la rentabilidad que conseguían los amos por los esclavos que pagaban jornal. Es decir, cuando los individuos trabajan para sí mismos, la rentabilidad es mayor que cuando lo hacen para un amo. Según los datos de Mello ("The Economics"), la rentabilidad de un esclavo adulto plenamente productivo que pagaba jornal para un amo estaba en torno del $11,5 \%$ al $15 \%$, mientras que esos mismos individuos y en esos mismos años tenían una rentabilidad por la manumisión del orden del $22 \%$ al $26 \%$. Sin embargo, esa tasa es menor que la de los grandes negocios de la época.

Claro, como hemos afirmado insistentemente, la libertad no era solamente un negocio; otras variables, como las culturales o políticas, ayudan a explicarla. Pero las decisiones motivadas por esas variables relacionadas con la ideología o la cultura no implicaban un salto al vacío económico. Si vemos nuestros cálculos para cada grupo etario, tal situación se torna evidente. La rentabilidad media de la manumisión para los niños siempre fue mayor al $10 \%$, y, aunque la dispersión fue alta, solamente en 1871 llegó a ser negativa la rentabilidad mínima, lo que probablemente sea producto del supuesto de llevar el cálculo sólo hasta 1888.

Igual sucede con los adultos, pues solamente en 1871 existieron algunas manumisiones en las que la TIR fue negativa. Así, siempre los adultos tuvieron promedios de rentabilidad mayores al $13 \%$. Como ya comentamos, la rentabilidad de los adultos era mayor que la de los niños. Otra vez, eso podría parecer 


\section{FRONTERAS}

evidente, sin embargo, no necesariamente lo es, pues los pequeños siempre tenían precios menores y también tenían mayor tiempo para el retorno de la inversión.

Con todo, la distancia entre la rentabilidad para niños y para adultos es más o menos constante. Sin embargo, existieron dos años en que las dos rentabilidades se acercaron $(1850,1861)$ y dos en que se distanciaron en más de 5 veces $(1841,1856)$. Pero esos casos no logran generar alguna tendencia clara. Tal vez, la única sea entre 1858 y 1861 cuando la rentabilidad de los adultos se redujo y llegó al nivel de los niños. Lo interesante es que esa caída se corresponde con la contracción en los pagos monetarios de finales de la década de 1850 y comienzos de la década de 1860 . Percibimos que los dos datos — rentabilidad y pagos monetarios - vienen de fuentes de información y universos estadísticos diferentes. Eso significa que la importancia de la crisis de 1857 para explicar parcialmente la manumisión es verificada por caminos distintos.

Para los ancianos, la rentabilidad es mucho menor que para los niños y los adultos. Aunque la media es del $11 \%$, en realidad el intervalo en el que se mueve el promedio anual es muy disperso y en varios años los valores mínimos de la TIR fueron negativos. Por ejemplo, en 1852, el valor mínimo de la rentabilidad fue de $-29,4 \%$ y la máxima, de $188,7 \%$. Con semejante intervalo es difícil (por no decir ingenuo) que el promedio de 37,3\% represente alguna cosas más allá de la propia dispersión de los datos. De este modo, la decisión de manumitir a los viejos era una elección que se explica fuertemente por motivaciones culturales (como el afecto) o políticas (por el posible papel que jugaban en las comunidades). Claro, también existían casos de rentabilidad positiva y alta, que quiere decir que había manumisiones en ancianos altamente productivos o que negociaron su libertad en condiciones bastante favorables.

\section{Conclusiones}

El cálculo de la rentabilidad de la inversión de recursos en la manumisión, teniendo en cuenta únicamente el precio de la libertad y los jornales, permite concluir que los esclavos que compraron la libertad no estaban haciendo un mal negocio. Eso no significa que la libertad se explique únicamente como un problema financiero; quiere decir que la libertad también se explica desde la economía y las finanzas de las familias esclavas. La realidad no es tan ambigua como algunos imaginan y, generalmente, las elecciones de los 
individuos se toman teniendo en cuenta varios y simultáneos ámbitos de la vida, como los valores culturales y los valores económicos. En este caso, la libertad que en el siglo XIX era un valor cultural también fue un negocio rentable. Aunque la rentabilidad de la manumisión en Río de Janeiro entre 1840 y 1871 era positiva y su valor era más o menos constante, ella por sí misma no explica las tendencias de la libertad. En otras palabras, la rentabilidad de la inversión en la manumisión no era, por sí misma y de forma aislada, una de las variables de decisión para las familias esclavas, pues cualquiera que fuera el individuo manumitido, esta inversión sería rentable. Por tanto, la elección de a quien manumitir era más compleja y debía envolver más aspectos.

La rentabilidad era el piso, el escenario mínimo, que garantizaba a los esclavos que el uso de sus recursos en la compra de la libertad no fuera un desperdicio. Claro, algunos esclavos conseguían salir del cautiverio sin desembolsar recursos, pero aquellos que sí pagaban no eran ingenuos. Esa condición de escenario mínimo, de garantía básica y primera, tenía alguna influencia en las tendencias de la manumisión, influencia que se nota en tres elementos. Primero, por una sustitución de la manumisión de niños por adultos a mediados de siglo que está vinculada al aumento de la rentabilidad de los segundos en comparación con los primeros. Segundo, entre 1852 y 1859, el total de manumitidos se disminuyó al mismo tiempo que la rentabilidad de adultos y niños tenía una pequeña caída. Eso no quiere decir que al momento de decidir si se manumitían, los esclavos hicieran algún cálculo como los aquí presentados. Quiere decir que la caída de la rentabilidad tenía un efecto sobre los recursos disponibles y, por esa vía, sobre las nuevas inversiones. Tercero, la caída de la manumisión monetaria de 1857 y 1859 está vinculada también a la reducción de la rentabilidad. Repitamos, no estamos diciendo que la rentabilidad sea la variable que explica completamente los ciclos de la manumisión. Estamos diciendo que la cantidad y la velocidad de los recursos que fluyen para la familia (que es lo que indica la TIR) influencia parcialmente las tendencias generales de la manumisión. Y decimos parcialmente, porque otras variables, como la circulación monetaria, juegan un papel central. Si la rentabilidad es la que genera la base financiera para la manumisión, los ciclos monetarios influyen en su tendencia. Ya mostramos que cuando los esclavos podían acceder, en términos marginales, a más moneda, ellos la usaban en el pago de la libertad; cuando esa moneda se contraía, los esclavos no podían hacer más pagos monetarios, aunque la libertad continuara siendo rentable. Por esa vía es que el ciclo monetario y el ciclo de manumisión están conectados. 


\section{FRONTERAS}

En contraste, el precio de la libertad juega un rol pequeño. Como ya mostramos, los esclavos eran poco sensibles a esos cambios. Por tanto, la función financiera que explica los pagos por la manumisión tiene dos componentes fundamentales: rentabilidad y moneda. La libertad era rentable a mediados del siglo XIX en Río de Janeiro y los esclavos estaban insertos en circuitos monetarios.

\section{Bibliografía}

\section{Fuentes primarias}

Archivo Nacional del Brasil (ANB).

\section{Fuentes secundarias}

Bentivoglio, Julio. "Política e diretrizes econômicas no início do segundo reinado (1840-1860): Limites e desafios da modernização". En Anais do V Congresso Brasileiro de História Econômica e $\sigma^{a}$ Conferência Internacional de História de Empresas. Abphe 2003. Consultado: 20 de junio de 2008, <http://econpapers.repec.org/paper/abphe2003/>.

Buescu, Mircea. 300 Anos de Inflação. Rio de Janeiro: APEC, 1973.

Cardoso, Ciro. Escravo ou camponês? O protocampesinato negro nas Américas. São Paulo: Brasilense, 1987.

Díaz, Rafael. El sistema esclavista urbano y urbano regional en Santafé de Bogotá. 1700-1750. Bogotá: Pontificia Universidad Javeriana, 2001.

Fragoso, João. "Sistemas agrários em Paraíba do Sul (1850-1885). Um estudo de relações não capitalistas de produção". Tesis de maestría UFRJ. Río de Janeiro, 1983.

Guimarães, Carlos Gabriel. "O Banco Rural e Hipotecário do Rio de Janeiro e o Pós-Guerra do Paraguai, 1871-1875". Anais do V Congresso Brasileiro de História Econômica e $6^{a}$ Conferência Internacional de História de Empresas. Abphe, 2003. Consultado: 6 de junio de 2008, <http://econpapers.repec.org/paper/abphe2003/>. 
IBGE. Estatísticas Históricas do Brasil: Series Econômicas, Demográficas e Sociais de 1550 a 1988. Río de Janeiro: IBGE, 1990.

Lima, Carlos. "Sobre a lógica e a dinâmica das ocupações escravas na cidade do Rio de Janeiro". Escravidão: ofícios e liberdade. Ed. Jorge Prata de Souza. Río de Janeiro: Arquivo Público do Estado do Rio de Janeiro, 1998.

Lobo, Maria Eulália. História do Rio de Janeiro (do Capital Comercial ao Capital Industrial e Financeiro). Río de Janeiro: Ibmec, 1977.

Mello, Pedro Carvalho de. "The Economics of Labor in Brazilian Coffee Plantations, 1850 a 1888 ". Tesis de doctorado. University of Chicago. Chicago, 1977.

-. "Expectation of Abolition and Sanguinity of Coffee Planters in Brazil, 1871-1881". En Without Consent of Contract: Conditions of Slave Life and the Transition to Freedom - Technical Papers Volume 2. Nueva Cork: WW. Norton \& Company, 1992.

Pelaez, Carlos M. y Wilson Suzigan. História Monetária do Brasil: Comportamento e Instituições Monetárias. Río de Janeiro: IPEA/Inpes, 1976.

Valencia, Carlos Eduardo. Alma en boca y huesos en costal. Una aproximación a los contrastes socio-económicos de la esclavitud. Santafé, Mariquita y Mompox 1610-1660. Bogotá: ICANH, 2003.

Fecha de recepción: 1 de febrero de 2008.

Fecha de aprobación: 15 de mayo de 2008. 